\title{
Critical Review of Social Network Analysis Applications in Complex Project Management
}

\author{
Cen-Ying Lee ${ }^{1}$, Heap-Yih Chong ${ }^{2}$, Pin-Chao Liao ${ }^{3}$ and Xiangyu Wang ${ }^{4}$
}

${ }^{1} \mathrm{PhD}$ Candidate, School of Built Environment, Curtin University, Perth, Australia

${ }^{2}$ Senior Lecturer, School of Built Environment, Curtin University, Perth, Australia

${ }^{3}$ Associate Professor, Department of Construction Management, Tsinghua University, Beijing, China (corresponding author). Email: pinchao@tsinghua.edu.cn

${ }^{4}$ Professor, School of Built Environment, Curtin University, Perth, Australia; International Scholar, Department of Housing and Interior Design, Kyung Hee University, Seoul, 12001 Republic of Korea

\begin{abstract}
Social Network Analysis (SNA) is a significant tool for analyzing networks in complex project management that examines the actors' interdependence in iterative and interactive social structures. It can also be used for non-social structure analysis. The potential of SNA could be extended significantly if its application to complex project management could be clarified. The objectives of the present review are threefold: (1) to clarify the interpretation of SNA metrics; (2) to identify its applications to complex project management knowledge areas; and (3) to reveal its uses in the non-social structures of complex networks. The authors conducted a qualitative systematic review based on 65 peerreviewed publications to identify 38 SNA metrics and concepts in nine complex project management knowledge areas. The findings show that SNA is a useful tool for application to the analysis of non-human resource networks and can be used for strategic planning and the improvement of project transmission efficiency and interdisciplinary interactions. The authors also delineated the future studies and the potential applications of SNA to provide new insights into advancing the use of SNA for analyzing and mitigating complex project management issues.
\end{abstract}

Keywords: Social Network Analysis; Complex Project Management; Metrics; Concepts; Application 


\section{Introduction}

One of the reasons for project failure is the increasing complexity of projects (Williams, 2002, 2005), or the underestimating of project complexities (Neleman, 2006). A project is said to be complex when it is structurally complex with many varied elements and interdependencies between those elements (Bacarrini, 1996), when there is uncertainty in the goals and methods (Williams, 1999), and when it is dynamic in nature (Whitty and Maylor, 2009). As such, construction projects are often categorized as being complex due to their inherent characteristics such as their occurrence in an ever-changing, complex environment, often with a high degree of risk (PMI-Construction Extension, 2015). The United States Federal Highway Administration (FHWA, 2010) defined complex projects as those projects that "have a high level of public or congressional interest; are unusually complex; have extraordinary implications for the national transportation system; or which are likely to exceed \$500 million in total cost." Cost and schedule overruns for such complex projects are common. For instance, the £798-million reconstruction of Wembley Stadium ran $80 \%$ over budget and was delivered four years later than originally planned (Brady and Davies, 2014). The College of Complex Project Managers (CCPM) (CCPM, 2008) defined complex projects as the projects with costs exceeding $£ 1$ billion with at least two criteria that are classed as being high. On the other hand, the Chartered Institute of Building (CIOB) Complex Projects Contract (CPC, 2013) did not define complex projects based on their capital value. Instead, they defined complex projects as those that involve the management of a construction period of more than twelve months, a design that is only completed during the construction, have multiple prime contractors, more than 20 subcontractors, multiple possessions and/or access dates, short-period possessions and multiple key dates and/or sectional completion dates. In the context of this paper, complex projects refer to 
construction projects with structural complexity, high uncertainty, and which require constant change in terms of progress and activity.

Given the complexity arising from the above three features of construction projects, an effective network analysis tool is, therefore, necessary to examine the interrelated elements involved in complex projects and their interdependencies for formulating project management strategies. However, the network analysis methods that the industry uses for the analysis of the complexity of construction projects' networks are subject to limitations. System models such as a flow chart that indicates the communication system of a massproduction firm (Stinchcombe, 1959) and a workflow diagram that demonstrates the project tasks and organizational model (Wong et al., 2009), are capable of conceptualizing and constructing a system that deals with linear processes and activities. Directed acyclic graphs (DAG), such as Bayesian networks, which the industry used to analyze safety risks under uncertainty in tunnel construction (Zhang et al., 2014), as well as fall accidents in steel construction sites (Leu and Chang, 2015), are more appropriate for modeling networks that contain no cycles. These techniques are less suitable for modeling more complex and interactive processes in a network that requires repeated and multiple ways of communication. Social network analysis (SNA), the focus of the present study, is a quantitative and qualitative analytical approach that emphasizes the integration of social science variables into complex project management. It is a network analysis tool that is appropriate for application to the analysis of the complexity of construction projects' networks which involve many objects and their interdependency relationships which are iterative and interactive (Pryke, 2012). For instance, Brass (1984) and Brass and Burkhart (1993) used it to examine the network influence, while Brass (1981) used it to examine the work flows related to positions. Brass et al. (1998) also used it to investigate how a relationship between actors can affect unethical behaviors while Labianca et al. (1998) and 
Nelson (1989) used it to examine conflicts between actors. The examination of social capital is important as individuals' social contacts convey benefits that create opportunities for competitive success for them and for the groups of which they are members (Labianca and Brass, 2006). Thus, the rapid increase in network research in management (Borgatti and Foster, 2003) has created a need for a review and classification of the work that is being done in this area.

Nevertheless, the potential of SNA cannot be realized if its potential applications have not been made clear to users. To date, researchers have developed many SNA metrics and concepts but their interpretation and application are rather unusual and complicated. For instance, degree centrality is a measure of the direct ties between one actor and other actors and is used to analyze the importance of stakeholders (Doloi, 2012), as well as identify leadership and influence positions within a network. On the other hand, another study asserted that degree centrality may not necessarily be a proxy for an actor's leadership position (Solis et al., 2013). Betweenness centrality, a measure of the extent of a node that stands between other nodes based on the shortest path, is an important indicator for actors having a major influence and control over the communication flow (Chowdhury et al., 2011). The way in which traffic flows in a network provides a useful means of determining centrality measures (Borgatti, 2005). This indicates that, to understand the application of different SNA metrics and concepts, particularly for centrality measures, it is essential to determine the types of networks and their flows.

None of the studies conducted to date have identified the state of development of SNA in complex project management. The common perception of the use of SNA is that it is limited to networks related to the social sciences. The nature of SNA, however, which analyzes the interdependencies of network objects, particularly of the network centralities, is such that it could be used to examine complex networks other than social structures, such as risk factor 
networks in which the causes of risks interact with each other. Reviewing the development of SNA in complex project management knowledge areas could reveal the usefulness of SNA when applied to diverse types of networks, which could help to enhance its application to complex project management.

Several previous review studies have been conducted to discuss the application of SNA to construction project management. Mead (2001) presented several ways of applying the results of SNA to the visualization of communication patterns in project teams. Chinowsky and Taylor (2012) reviewed SNA-related publications in engineering project organizations to demonstrate the evolution of the use of SNA. Zheng et al. (2016) conducted a review of SNA applications from the aspects of organizational and individual contributions, coverage topics, research methods, and citations in construction project management research. Nevertheless, none of the studies examined the application of SNA metrics and concepts in detail; nor did they explore their application to complex project management knowledge areas.

Based on the discussions above, the authors conducted a qualitative systematic review to: (1) clarify the interpretation of SNA metrics; (2) identify the application of SNA to complex project management knowledge areas; and (3) reveal its use in the non-social structure of complex networks. The authors selected sixty-five (65) SNA academic publications related to complex project management research from which the authors identified, analyzed, and discussed thirty-eight (38) SNA metrics and concepts related to nine (9) complex project management knowledge areas consisting of diverse types of networks. The focus of this study was not merely the exploring of SNA applications and analyzing current trends in complex project management knowledge areas, but the provision of significant insights to practitioners and researchers for advancing the application of SNA in future complex project management research. 


\section{Literature review}

\section{Complex project management}

A complex project is distinguished from a traditional project in terms of its structural complexity, that is, its many and varied interrelated parts, to be operationalized in terms of differentiation and interdependency (Bacarrini, 1996). Williams (1999) asserted that uncertainty should be added to the dimension of project complexity due to the instability of the assumptions upon which the tasks are based. However, structural complexity and uncertainty are not sufficient to give the full dimensions of a project's complexity without considering the dynamic effects of changes to the structural elements. The elements interacting as they change (dynamic nature), cause further changes in other parts of the system (Whitty and Maylor, 2009). The complexity is apparent in technological (Davies and Mackenzie, 2014), organizational (Qureshi and Kang, 2015), environmental (Nguyen et al., 2015) and knowledge sharing (Ahern et al., 2014) aspects. Construction projects are typically viewed as complex projects as they produce complex products which involve the interaction of many systems. A change to one system will affect other systems (Williams, 1999).

There are two distinct viewpoints as to how complex projects should be managed. On the one hand, it is asserted that project complexity will influence the use of processes and techniques (Yugue and Maximiano, 2012), such as strategic design to project delivery, choice of contracting model, criteria and process selection of team members, and the tool sets used in the planning and delivery of the project as outlined in the Complex Project Manager Competency Standards (CCPMS, 2012). Hence, complex projects cannot be managed based on the principles of traditional project management. Various complex project management frameworks and related research have been developed to deal with the complexity of the projects. For instance, Shenhar (2001) identified four levels of technological uncertainty from 
low-tech to super-high-tech and three types of projects, namely, assembly projects, system projects, and array projects, to address the various levels of complexity from an assembly component with a defined function, such as a computer console, to an integrated dispersed collection of systems used to achieve a common goal such as an airport. Each type of project requires different organizational arrangements and project processes corresponding to the level of complexity. Bosch-Rekveldt et al. (2011) developed a framework for analyzing 50 elements contributing to the complexity of the technical, organizational, and environmental (TOE) aspects, in which the elements are divided into various categories, subcategories, and elements, thus allowing stakeholders to discuss the various levels of aggregation and aspects, which make a specific project complex. Vidal et al. (2011) proposed project complexity scales and subscales to highlight the most complex alternatives and their principal sources of complexity within a set of criteria and sub-criteria, which exist in a hierarchical structure. Geraldi et al. (2011) presented a contingency framework consisting of five dimensions, namely structural, uncertainty, dynamics, pace, and socio-political complexity, to help individuals and organizations make the right choices on addressing the complexity of each project. Gsansberg et al. (2013) developed a "complexity footprint" that helps the complex transportation project manager identify the sources of complexity; this was developed to allocate appropriate resources for addressing the factors that constrain project delivery. Davies and Mackenzie (2014) developed a two-integration framework, consisting of the "meta-systems integration" level and "system integration" level to allow organizations to understand an overall system with external interfaces with multiple stakeholders and thus coordinate the integration of the component parts and self-contained subsystems to coordinate the interdependencies with other parts of the overall array. The analysis of different project complexities allowed the further study of its impact on technological learning and new product development outcomes, namely project success, development speed, and product 
entry timeliness (Ignatius et al., 2012). It also enabled the proposal of a quantitative risk assessment methodology to analyze the emergent risks associated with the interactions in a system of complex systems (Naderpajouh and Hastak, 2014) and the examination of organizational control theory (Liu et al., 2014). On the other hand, it is argued that knowing whether a system is complex does not mean that the manager requires complex tools to control or manage it. Traditional methods may continue to be appropriate provided they work well for stakeholders (Whitty and Maylor, 2009). CCPMS (2012) acknowledged the importance of project management knowledge areas from Project Management Body of Knowledge (PMBOK) in managing complex projects and defined a standard that should be observed by complex project managers.

\section{Network analysis methods used in complex project management}

Common network analysis approaches applied to complex project management take the form of linear graphical representations such as the Critical Path Method (CPM) (Tavakoli and Riachi, 1990). This task network analysis allows continuous progress monitoring in a changed environment to identify the critical activities. Various scheduling methods are then developed to deal with uncertainty in activities and project durations such as reactive scheduling (Sabuncuoglu and Bayiz 2000), stochastic scheduling (Demeulemeester and Herroelen 2002), fuzzy scheduling (Slowinski and Hapke 2000), proactive scheduling (Davenport et al. 2001), and sensitivity analysis (Hall and Posner 2004), but they fail to consider the logical relationship among the activities (Wang et al., 2014) and ignore the most important interface management function in complex project management.

Directed acylic graphs such as Bayesian networks are typically used to predict probabilities and determine why causal networks are not cyclic. For instance, Gerassis et al. (2017) used a Bayesian network to quantify and predict the specific causes of different types 
of accidents. Again, it is less appropriate to analyze whether a network contains a cycle. As discussed earlier, complexity arises in a project and organizational context due to many interrelated parts. These depend on each other to accomplish the tasks. These parts include social elements such as stakeholders, human resources, communications, knowledge sharing, trust, and risks. The social context is interactive and the social elements influence each other.

System Dynamic Modeling (SDM) is very useful for analyzing complex structures, which consist of many interrelated variables with non-linear and non-dyadic relationships. It offers the opportunity to simulate a problem by investigating its results and behavior, making the framework useful for policy testing, what-if scenarios, or policy optimization (Barranquero et al., 2015). Although SNA is clearly very different from SDM as it focuses on social actors and their interrelationships, SNA can indeed be incorporated into the structure analysis of SDM as a complement to SDM. One the disadvantages of SDM is that it lacks operational detail (Williams, 2002). The SDM modeler is often confronted with two problems, namely, (1) how to best describe or model the system and, (2) where to change the system to produce more favorable system outcomes. Centrality analysis of SNA can help SDM modelers address the latter problem by providing a screening tool for finding effective levers in large SD models (Schoenenberger and Schenker-Wicki, 2014).

SNA can complement other research methods for examining uncertainty elements, which are non-social structures in complex projects, and thus present a richer diagram. For instance, SNA can integrate with a link probability model such as the Monte Carlo simulation method to provide a more accurate prediction for network data (McCulloh et al., 2010). SNA allows the examination of project governance using a common methodology for all aspects of governance (Pryke, 2005) in an analytically quantifiable manner, principally through the application of centrality measures (Pryke and Pearson, 2006). The basic structure of SNA consists of nodes (vertices/actors) and ties (a line/ link between two nodes in a network) 
which are used to detect and interpret patterns related to social ties between vertices. The line is directed (arc) or undirected (edge). For SNA, de Nooy et al. (2001) represented a network by a graph and additional information on the nodes or the lines of the graph. Chowdhury et al. (2011) demonstrated SNA in a one-mode or two-mode network with two types of nodes. An example of the two types of nodes in a network would be stakeholders and their associated risk factors involved in a project (Li et al., 2016).

\section{SNA application}

The SNA metrics and concepts applied in complex project management research can be classified into four categories depending on their role in a network: formation mechanisms of a network, centrality, the connectedness of a network, and the network topology. The formation mechanisms of a network are related to the status of a node and the degree of its power as represented by ties in a network. Direct tie measures the number of a node's direct links to other nodes (Wasserman and Faust, 1997), whereas indirect tie measures the number of links of a node that can be reached through its immediate nodes (Ahuja et al., 2003). Tie strength is a measure of the strength of a relationship between two nodes. It is the sum of the frequency of interaction, the intensity of emotion, rapport, and reciprocity (Granovetter, 1973). In terms of the overall network, network density is used to indicate the strength of the connections in a network (Marsden, 1993). Typical measures of cohesion include network density, reciprocity, clique, and structural equivalence. Alba (1973) also measured the cohesiveness subgroup ratio by comparing the strength of the ties within a subgroup to nodes outside a subgroup.

Faust (1997) used centrality to indicate the centralized position of a network. In a network with high centrality, only a limited number of actors function socially, while the others receive, transfer, and deliver information (Liao et al., 2014a). At the node level, degree 
centrality is used to represent the structural position of actors in a network (Hossain, 2009b). Bonacich power centrality refers to actors who are tied to central actors having higher prestige or centrality than those who are not (Bonacich, 1987). PageRank is another centrality measure devised by Brin and Page (1998) that counts both the quantity and quality of the followers of a node to determine the degree of influence of that node. Depending on whether an actor has more incoming or outgoing ties in a network, the actor is said to have a high indegree centrality or high out-degree centrality, respectively (Liebowitz, 2006). Another type of centrality measure is 2-step reach, which sums the number of nodes within two steps (thus including the adjacent nodes' degree centrality) of a node (Borgatti et al. 2002). Closeness centrality measures the length of the path from one node to all other nodes (Hossain and $\mathrm{Wu}$, 2009). The measurement of distance includes diameter and geodesic distance. Geodesic distance is the shortest path between two vertices (De Nooy et al., 2011), whereas diameter is the longest geodesic distance between any pair of nodes (Torres et al., 2016). As the path between two nodes becomes shorter, the efficiency with which information is transmitted will increase. Therefore, the average path length is an indicator of the network efficiency (Lin, 2014). An actor with a high betweenness centrality value has some control over the network as other actors depend on this actor to connect to each other, as in the case of brokerage (Chowdhury et al., 2011). If there is a structural hole (a form of discontinuity in the flow of information) in a network, the person holding the brokerage position can capture a strategic position to connect or disconnect a group, and thus, enjoys a competitive advantage relative to other nodes (Maoz, 2010). Eigenvector centrality is an extension of degree centrality and is proportional to the sum of the centralities of a node's neighbors (Estrada and RodríguezVelázquez 2005). Status centrality (also known as Katz centrality) is similar to eigenvector centrality in that it also reflects a stakeholder's influence within a network. It measures the 
number of direct successors and predecessors of a node, as well as the secondary nodes that are indirectly linked to the focus node via the node's immediate neighbors (Katz, 1953).

SNA is also capable of assessing the level of connectedness among actors and subgroups in a network. At the node level, the clustering coefficient is the percentage of two paths in a network that are closed (De Nooy et al., 2011). Structural equivalence describes any two nodes that have similar and identical ties (McCormick et al., 2010). Reciprocity is the ratio of the number of reciprocated node pairs to the number of connected node pairs (Lee et al., 2016). Transitivity indicates the possibility of node A having a connection with $\mathrm{C}$, if A knows B and B knows C. It is the proportion of triads and the number of triples (Bruggeman, 2013). Point connectivity represents the minimum number of nodes that must be removed from the graph to cause the graph to become disconnected (Wasserman and Faust, 1997). Partitioning is used to classify the nodes in a network (De Nooy et al., 2011). It involves the assignment of a similar color to nodes or edges that share the same values for a given SNA parameter or node/edge attribute (Hernandez-Garcia and Suarez-Navas, 2017). Modularity measures the strength of the division of a network into modules (groups or clusters). It distinguishes the number of existing links in a partition and the expected number of links that could appear between the nodes of the partition (Nik-Bakht and El-Diraby, 2016). Homophily explains how, when offered a choice, people prefer to choose others who are similar to themselves (Kleinbaum et al. 2013). When the relationship between the nodes is compact, it is said to form a core. When the relationship between the nodes in another group is loose, it is regarded as being a periphery (Chang and Zhang, 2013). Boundary spanner is another term that is typically used to describe the role of an actor as a mediator to conciliate the negative effects arising from differences in status and culture (Di Marco et al., 2010).

This study addresses the concepts of components, small-world networks, scale-free networks, and egocentric networks with respect to network typology. A component is a 
maximally connected sub-network (De Nooy et al., 2011). A giant component represents the largest isolated sub-network usually identified in a random SNA network (Liu et al. 2015). In contrast to the giant component, Blackburn (2002) observed a small-world network when most nodes are not neighbors, but they can reach each other in a small number of steps. An egocentric network is a personal network. This scale-free network has a degree distribution determined by the social group's size distribution. It presents SNA data using a random graph model to observe the expected network structure within a collected data set (Comu et al., 2013). Note that, although the SNA metrics and concepts have been discussed in various categories, there are always interrelated dependencies in the context of a study.

\section{Complex project management knowledge areas}

The complex project management knowledge areas discussed in this study were obtained from the specific project and organizational applications. The classification of the SNA applications was performed in accordance with the project management knowledge areas categorized by the Project Management Institute (PMI)-construction extension (2016) and management knowledge areas as stated in the PMI (2013). The PMI-construction extension (2016) considers the complex nature of construction projects in its deliverables. Moreover, the authors believe that analyzing the state-of-the-art of SNA in complex project management should begin with its application to each project management knowledge area. Network behavior is added as one of the knowledge areas in the present study if the references found are rather general and could not be applied to any of the areas stated in the PMI references. Thus, network behavior is classified as an independent area as the network analysis for understanding organizational behavior is also important in complex project management. The mapping of complex project management knowledge areas to SNA applications provides an easy reference for educators, practitioners, and researchers who need to learn about the types 
of networks to which SNA is applied and which could help to uncover any non-social structure networks that are applied to the SNA in complex project management knowledge areas. Table 1 lists the complex project management knowledge areas identified in this study.

\section{Review methodology}

A qualitative systematic review method is selected as it not only integrates and compares the findings from the papers identified, but it also looks for themes that lie in or across the papers (Grant et al., 2009). The systematic review procedures were simulated from the steps outlined in Moher et al. (2009). The steps of systematic review begin with identification of the primary studies through database searching. Then, the authors conducted an intensive literature search of relevant papers listed in the Scopus database. The keywords used in the search were "SNA project management," "SNA complex project," "SNA engineering project," and "SNA construction project" with no limitation regarding the year. The authors obtained 95, 30, 30, and 56 document results found using these four keywords, respectively. The papers selected for the study were all peer-reviewed to ensure the quality of the data obtained. Thereafter, the authors screened the papers found from the database to identify and confirm whether the SNA application described in the papers was related to construction projects. The authors assessed the full text of articles to identify their eligibility to be included in the study. The selection of papers was based on the context of construction projects as such projects consist of many complex elements which could be applied to complex projects. If a paper provided only a general discussion of SNA without showing the application of SNA in construction project networks, the paper was excluded from the study.

Sixty-five peer-reviewed journals that discussed the SNA applications in complex project management ranging from 1998 to January 2017 were identified in the present study (Fig. 1). 
From 1998 to 2010, the numbers of papers that mentioned SNA in relation to complex project management research were within a range of 0 to 3 per year. After 2010, SNA becomes a popular analytical tool as the number of papers making mention of it increases sharply, reaching a peak of 11 in 2013 . Table 2 lists the journals that were reviewed as part of the study.

The authors then categorized each paper into different knowledge areas based on the main purpose of the SNA study. Although a paper may span several knowledge areas, the authors grouped it into a certain knowledge area based on the main purpose of the study, which contributes to the output of the knowledge area. Table 3 lists the papers reviewed in the study which were grouped into different knowledge areas.

During the data analysis process, the authors prepared the data according to the purpose of the SNA study in each knowledge area, the type of network study and SNA metrics, and the concepts discussed in each paper. One of the authors compared, investigated, and discussed the application and interpretation of the SNA metrics and concepts that were used for similar types of networks and their purpose in each knowledge area in the manuscript. The other two authors audited and validated the analysis to ensure the credibility of the systematic review. Finally, the authors abstracted the findings based on the three objectives identified in the Introduction.

\section{Analysis of SNA applications in complex project management}

The authors grouped the SNA metrics and concepts identified from the 65 journals according to the knowledge area and then aggregated them into Microsoft Excel. The authors conducted the analysis based on two modes, with one representing the knowledge areas and the other describing the SNA metrics and concepts. After summing the SNA metrics and concepts in each knowledge area, the authors exported the data in the Excel spreadsheet to UCINET v. 6 
for two-mode analysis. Degree centrality was used to identify the most connected SNA metrics and concepts in each of the complex project management knowledge areas. The degree centrality in this two-mode network study represents the maximum degree of a node given by the number of nodes in the opposing set (Borgatti and Everett, 1997). This implies that the maximum degree for an SNA metric or concept is the total number of knowledge areas, while the maximum degree for a knowledge area is the total number of SNA metrics and concepts. Table 4 lists the results of the analysis.

Table 4 lists the centrality position of the 38 SNA metrics and concepts in 9 knowledge areas. A higher centrality value indicates that more SNA metrics and concepts are applied to the analysis of a network. From the viewpoint of knowledge area, the results show that most of the SNA metrics and concepts discussed applied to communications management. A wider application of the SNA metrics and concepts is also evident in procurement management and network behavior. With respect to SNA metrics and concepts, network density, degree centrality, and betweenness centrality recorded the highest centrality values relative to the other nodes. This implies that these metrics are the most influential measures in the analysis of complex project networks. In-degree centrality also has the second-highest centrality values, suggesting that it is also significant to complex project networks. The authors discuss the application of SNA metrics and concepts to complex project management knowledge areas in the subsections below.

\section{Network behavior}

In the context of network behavior, SNA was used extensively to analyze a firm's collaborative behaviors. Network density was used to determine the connectivity level of firms (Lu et al., 2015). A low-density network has a dispersed structure (Akgul et al., 2016), suggesting a low level of cohesion (Sedita and Apa, 2015). However, this is subject to the 
network size (Park et al., 2011). This metric was also used to perform measurements in conjunction with degree centrality to identify state-owned organizations such as designers and contractors. Cao et al. (2016) identified these by observing nodes that had large linkages with those occupying central positions. Lu et al. (2015) used degree centrality to identify the importance of nodes such as the clients of private projects and the prestige gained by firms owing to their winning of public projects (Sedita and Apa, 2015). Large firms who had higher out-degree centrality and betweenness centrality were more likely to make a profit as they attracted more partners and had a higher social influence (Park et al., 2011). However, the betweenness centrality of firms had no impact on the likelihood of their winning public projects (Sedita and Apa, 2015). Park et al. (2011) identified closeness centrality as being an insignificant measure for small firms who wanted to gain by engaging in diversification and close cooperation and for firms who wanted to win public projects (Sedita and Apa, 2015). Akgul et al. (2016) used Eigenvector centrality to determine the significance of firms that typically had the most experience and which were thriving in terms of international collaboration. The numbers of direct ties and indirect ties were also seen to boost the capabilities of a firm (Park et al., 2011).

Liu et al. (2015) used the average path length to investigate the extent of the connectivity of two firms over different time spans. This enabled the assessment of the evolution of collaboration behaviors. The average path length and clustering coefficient identified the small-world properties of firms that exhibited a high possibility of forming small-world properties (Cao et al., 2016). Akgul et al. (2016) used connected components to identify the leading companies and giant components to determine the appearance of large contractors' components in the collaboration network. Liu et al. (2015) found that the scale-free network was particularly important in determining certain revolutionary regularities such as the regional, professional, and social capital preferential attachment of firms engaging in 
collaborative behaviors. Homophily also proved useful in ascertaining owners' tendencies when selecting new project partners with specific similarity attributes like firm ownership and relevant BIM experience. Cao et al. (2016) used a core-periphery analysis to understand the persistence of the uneven distribution of collaborative ties for networks over different time spans.

\section{Stakeholder management}

To examine stakeholders' influence networks, Doloi (2012) used degree centrality in conjunction with the social performance index to determine the importance of stakeholders. As a result, it was found that degree centrality could be associated with the stakeholders' power and interest in a project). However, in another influence network, status centrality was identified as being a significant measure for determining the stakeholders' prominence, while using the out-status centrality to identify the degree to which one stakeholder affected others. Yang et al. (2011) used the status centrality to adhere to the project management team's roles.

To analyze trust networks of contractual and non-contractual relationships between project stakeholders and their impact on project performance, Swan et al. (2007) used direct ties to determine the trust between two nodes. It should be noted that trust is not equivalent between two nodes given the fact that while A may trust B, B may not necessarily trust A.

To analyze the social core functions of project stakeholders (Almahmoud and Doloi, 2015), the researchers used eigenvector centrality to quantify the importance of the stakeholders and social core functions. It was incorporated into a stakeholder's social sustainability health check dynamic assessment model to identify problems affecting project performance enhancement. 
To investigate the communications networks of the community of interest, researchers used various measures to determine the influence of the nodes. Betweenness centrality was used at the initial stage to identify the online community that has a major influence on information flow, while degree centrality was used at a later stage to determine the users' influence based on their occupations, affiliations, and locations (Williams et al., 2015). However, in another study, the researchers integrated PageRank with semantic analysis to determine the members' degree of influence and to detect a community in a complex project discussion network. The network consisted of a knowledgeable e-society in which members could freely access information about a complex project and discuss its different aspects. Furthermore, the modularity maximization algorithm was used to determine the communication density of a partitioned community (clusters) by performing matching with high computational efficiency and accuracy (Nik-Bakht and El-Diraby, 2016).

Although degree centrality was viewed as being the determinant of influence and prominence position in the stakeholders' influence networks, it was not necessarily a proxy in an information exchange network. In this context, it indicated actors through whom information frequently flowed, and was used to identify the drivers of stakeholder behavior associated with their roles in projects such as central connectors, boundary spanners, information brokers, and peripheral persons. Cluster analysis was used to demonstrate stakeholders' tendencies to develop ties with those who shared disciplinary knowledge (Solis et al., 2013).

\section{Schedule management}

There were very few studies about the use of SNA in schedule management. Only two studies were conducted to analyze the interactions of trades for identifying the key trades to be used in a critical path method (CPM) schedule (Wambeke et al., 2012; Wambeke et al., 2013). 
Both selected degree centrality and eigenvector centrality as important measures for identifying the key trades. In addition, trades having greater frequencies were identified as having stronger ties as they often worked together with other trades that were close to each other (Wambeke et al., 2013).

\section{Quality management}

The application of SNA to quality management was found to be related to the improvement of project deliverables. To analyze the interrelationships between the defect causes of a complex engineering system, Aljassmi et al. (2013) used in-degree centrality to determine the extent of a cause that originated from other causes directly linked to it. This was particularly important for determining the initiating causes of the defect. Closeness centrality determined the closeness of a cause to all other latent conditions by considering its preoperational capacity. Tie strength was used to determine the causal strengths of the causes of defects based on conditional probabilities.

To determine the essential quality management practices of flash-track projects, outdegree centrality to identify the extent of a practice that enabled other practices. On the other hand, the extent to which a practice depended on other practices was measured by applying the in-degree centrality measure. Eigenvector centrality was also used to identify the importance of a practice by determining the feasibility of the said practice as a consequence of other practices. Tie strength was measured to determine the relational intensity of a practice with other practices. (Pishdad-Bozorgi et al., 2016).

To uncover the latent job-site management problems of a dam project, Lin (2014) investigated the order management network, technological-consultation network, personal social networks of the owner, joint venture partner, engineering consulting firm, and subcontractors involved in the project. The network density in the order-management network 
represented the abundant resource infusion and institutional enforcement of the projects. Degree centrality was used to analyze the structure positions of the three networks to discover any unrealized social patterns. For instance, the site manager and principal engineers were found to be the central figures in the order-management and technological consultation networks, but they became outliers in the interpersonal social network. Two network topologies were proposed to ensure the effective execution of the project. One was a giant network of two interconnected hierarchical structures consisting of the owner and contractor that could increase the order and information transmission efficiency within the networks. A small-world architecture was proposed for the technical consultation network to promote interaction between the interdisciplinary teams that might lead to a technology revolution while avoiding engineering errors caused by the misalignment of technological interfaces (Lin, 2014).

Woldesenbet et al. (2015) used SNA as a complementary tool for improving construction project planning in addition to the existing complex project SNA. For a highway datainformation-decision network, efficient highway infrastructure data was determined by using the network density to determine the reliability of the information used to support the decision-making process. Degree centrality was used to determine the most influential highway data that generated decision-making information. Furthermore, betweenness centrality was deemed important in the context of highway data management as it measures the degree to which nodes acted as mediators between data and decisions. High eigenvector centrality data indicated data that had the greatest number of connections, while high eigenvector centrality information provided the greatest number of paths to create a bridge between the data and decisions that were considered critical (Woldesenbet et al, 2015).

To improve the quality of traffic planning, El-Adaway et al. (2016) used tie strength to identify the impact on a traffic intersection network. The nodal degree was used to determine 
the criticality of intersections by determining the opportunities and alternatives to reach anywhere in the network. The 2-step reach was used to determine the importance of intersections in the local area when the connection strengths of the nodes were very close to each other. Intersections located on a loop roadway had a lower betweenness value than the intersections of a roadway that passed through a city center and connected many other roadways. Eigenvector centrality was also useful as it considered the high-traffic-count connections to a node (El-Adaway et al., 2016).

There is very little evidence of the significance of SNA measures in the application of SNA to the improvement of the quality of water distribution network planning in vulnerable areas. Previous studies were unable to prove that the most connected node was that with the highest centrality (the most important node) (Guimera et al. 2005; Cadini et al. 2009). The studies under consideration did not consider the service of network flows nor did they remove the nodes to gauge the effect on performance. Graph theories such as scale-free/power law, small-world, and the random graph model, as well as centrality measures such as degree centrality, betweenness centrality, and closeness centrality were used to simulate the distribution flow in a hydraulic model. A strong correlation between the distribution flow through the nodes in the network and the network average path length suggested that parts of graph theory were applicable to the engineering network. Dunn and Wilkinson (2013) found a strong correlation between the three centrality measures and the flow through the corresponding node in the scale-free network.

\section{Resource management}

In the analysis of actors' innovation awareness and the influence of their opinions, centrality measures were not found to be significant but the network orientations became important. An 
overtly egocentric network adversely affected awareness and influence because of the actors' ignoring messages from outside the network (Larsen, 2011).

Network density was used to assess the connectivity in the case of other types of resource networks. This included the client, referral, financing, authority, supplier, and internal market networks of construction firms (Badi et al., 2017); order-oriented networks and social networks of complex construction firms (Li et al., 2011); advice networks, trust networks, friendship networks, information networks, sharing willingness networks, and cognitive networks of public employees (Lin and Tan, 2014); information, advice, brokerage, and funding networks of owners of small construction firms (Pryke et al., 2011). For an egocentric firm network, a high network density value indicated that the firm was better placed to access an exclusive market. In contrast, a low network density indicated that the firm had fragmented suppliers and client markets (Badi et al., 2017). Pryke (2011) used this metric together with degree centrality to determine how small firms developed essential resources to survive and grow. Badi et al. (2017) used degree centrality to determine the prominence and privileged position of a firm for controlling resources in the business environment (Pryke et al., 2012), and that firm's competitive ability to manage complex projects (Li et al., 2011). In-degree centrality was useful for identifying the importance of public employees who were recognized by others and who retrieved information from others. Employees with high betweenness centrality were found to be important connective candidates (Lin and Tan, 2014).

Tie strength was significant in resource networks as an indicator of the potential use of resources of firms in a network (Badi et al., 2017). Weak ties were advantageous for the individuals in a resource network as they could exert their power and control over resource flows while breaking their connection with others. A brokerage is an actor who facilitates the complementary interests of unconnected actors. Although not a resource itself, a brokerage 
formed a crucial aspect of a small business's resource provision network. Nevertheless, Pryke et al. (2011) proved that the frequency of communication for any resource was an imperfect proxy to tie strength given that there was no correlation between them. In addition, in a resource network, Li et al. (2011) deployed structural equivalence to determine the key actors in a network who had cliqued to set a specific control strategy.

\section{Communications management}

Most of the SNA studies were applied to communications management. Flows in communication networks represented coordination, information, negotiation, and knowledge exchanges that created trust. A low-density value indicated that the network focused on individuals rather than on collaboration over the network (Chinowsky et al., 2010). High density, high degree centrality, and low betweenness centrality in communications networks indicated fewer structural holes (Heng and Loosemoore, 2013). High-density and strong ties in information exchange networks developed trust. Therefore, the information required by actors was easily acquired (Pauget and Wald, 2013).

Various types of centrality applications were found in different communication networks. Just as degree centrality indicated the prominence and influence of actors' positions, centrality for the whole network was used to enable a comparison of knowledge exchange networks in collaborative and comparative procurement systems (Ruan et al., 2012). For negotiation networks, a node occupying high degree centrality indicated its importance to project participants' discussions (Di Marco et al., 2012). In information networks, it represented the roles of project team members when information flowed through them (Thorpe and Mead, 2001). A superintendent officer associated with a high degree of centrality typically played a crucial role as almost all the communication between trade contractors was found to flow through him/her (Priven and Sacks, 2014). The in and out- 
degree centrality could be measured simultaneously based on the number of ties connected to an actor. If an actor in a network was an important provider of information (out-degree centrality) and he/she had enough connected ties, then his/her network position visibly corresponded to the role of a coordinator (Pauget and Wald, 2013). In coordination networks, it was proven that actors who had a high degree of centrality were more capable of coordinating a project (Hossain, 2009a; Hossain, 2009b; Hossain and Wu, 2009).

In communications networks, actors with high betweenness centrality could utilize their network advantage to manipulate the information flow for their own interests (Loosemoore, 1998) and this was viewed as a position of control and leadership (Heng and Loosemoore, 2013). Although an actor with a higher closeness centrality was interpreted as depending on others to act (Loosemoore 1998), it was viewed as an advantageous position for an actor. Efficient solutions corresponded to one firm having the shortest communication paths to the other firms (Dogan et al., 2014).

In communications management, network constraints and tie strength were viewed as being tools for identifying the potential value of brokering a structural hole. A high potential to broker a structural hole existed when a facility manager had strong connections with the IT and security departments but direct communication with each other was difficult (Heng and Loosemoore, 2013). The clustering coefficient was useful for determining the density of negotiation networks when there was repeated emphasis on the boundary objects made by the project participants (Di Marco et al., 2012). The communications efficiency was determined from the average path length and network density. When the average path length was long and the density was low, knowledge transfer was not effective (Tang, 2012).

To strengthen the communications, Di Marco et al. (2012) developed reciprocity and transitivity to create trust and alliance formation that would lead to a better negotiation outcome. Pauget and Wald (2013) used homophily to identify the roles of members who 
shared a common culture and language with others in the network, and thus acted as mediators in the network. Loosemoore (1998) used structural equivalence to identify actors who had similar communications patterns. However, Borgatti and Everett (1989) also showed that actors with the same connection patterns might not be playing a similar social role. Rather, they may be in competitive positions. Clique enabled the team to work collaboratively. The manager had to be aware that the introduction of new communications systems or the separation of teams into separate locations could affect the cliques in a network (Houghton et al., 2015).

\section{Risk management}

SNA was used to investigate project stakeholders' risk networks and examine the coordination networks of those emergency response teams who constituted part of the elements in risk control. A higher network density indicated that there were more stakeholder risk interactions in the risk networks (Li et al., 2016) and better coordination for members' social control in the coordination networks (Mohammadfam et al., 2015).

The determinants of the nodes' influence when using centrality measures in risk and coordination networks were different. For coordination networks, network Mohammadfam et al. (2015) used out-degree centrality to identify those members who had a greater influence. On the other hand, for risk networks, stakeholders who had a larger gap degree tended to exert a stronger influence on their neighbors ( $\mathrm{Li}$ et al., 2016). Furthermore, Yang and Zou (2014) identified out-status centrality as being a significant measure as nodes with a higher value had a greater degree of influence. Betweenness centrality was important for enabling the reaction of a gatekeeper when controlling influence. The absence of nodes with a high value of this measure reduced the influence of stakeholders' risks in the network (Li et al., 2016). 
The cohesion levels of risks and coordination networks were also dissimilar. The cohesion level in a risk network was represented by the network density and average path length. A high cohesion value indicated that a complicated risk network, corresponding to a longer distance, was required to incur a risk that would trigger the involvement of another member (Li et al., 2016). In a coordination network, cohesion was indicated by network density, degree centrality, reciprocity, and transitivity. A high reciprocity indicated better mutual connections with another member, while high transitivity showed that each member was equally interested in maintaining their coordination. These two measures were significant in that they contributed to network stability by developing trust among members (Mohammadfam et al., 2015).

For a risk network, Yang and Zou (2014) used brokerage to denote the roles of risks (coordinator, gatekeeper, representative, consultant, and liaison) while partition provided a means of influence mechanics among the various types of risks. For instance, in a brokerage relationship with a coordinator, if node A received a link from node B within a given partition, and then sent a link to node $\mathrm{C}$ in the same partition, then node $\mathrm{A}$ gained 1 coordinator score. Nodes with high brokerage scores in dissimilar roles required more attention as they had a propagating effect and complicated the overall network ( $\mathrm{Li}$ et al., 2016). The partition metric helped project managers to identify the interactive characteristics among various risk types, improve coordinated decision-making, and enhance communications between the stakeholders when dealing with risks (Yang and Zou, 2014).

\section{Procurement management}

The networks studied related to procurement management consisting of the contractual networks and project governance networks involved in project delivery. Lee et al. (2016) used network density to model the likelihood of private and government contracting. If 
private contracting had a higher value, the private clients were more likely to enter a contract with a construction firm. Pryke (2005) used degree centrality to indicate the extent of an actor's power associated with his/her specialized knowledge and positions conferred under the contract terms and conditions. West (2014) used betweenness centrality to test the extent of a broker's role in the market power diffusion among alliance partners. Partners with limited alliances had a low closeness centrality, and consequently a restricted information flow through them. The actor with the highest eigenvector centrality score was considered the most important member affecting the main pattern of the distances of all actors, whereas actors with a low eigenvector centrality score were considered as peripheral actors (Chowdhury et al., 2011).

With respect to the interconnectedness of contractual members, the point connectivity measured the vulnerability of a firm in a network to determine its interdependency in a network (West, 2014). Component analysis enabled the analysis of connectivity between nodes when the network was configured. For instance, Lee et al. (2016) segmented a network consisting of one component into more components once the cut points were removed. Zhang et al. (2015) used clique analysis to identify Integrated Project Delivery (IPD) candidates with a high centrality in the team member selection system. Clique analysis investigated the mutual interactions among the project members and their willingness to share their experiences. Through clique analysis, good combinations of IPD team members were identified.

Contractual networks were also contextualized using network topologies such as small world and scale-free networks. By analyzing a network with respect to its clustering coefficient, average path length, and diameter, the small-world property could be identified. This determined whether the number of competitors affected the link closeness between firms, and indicated monopoly in the construction market. Scale-free networks were 
characterized by a limited number of well-connected hubs where the rich got richer. Lee et al. (2016) used this to identify the preferential attachment of new firms that tended to connect with firms that had many links.

\section{Health, Safety, Security, and Environmental (HSSE) management}

SNA studies of HSSE management involved analyzing safety teams' communication patterns and an accident network. Network density (frequency of interaction) was applied to safety communication and training networks to understand the low- and high-performing teams' connectivity in resolving safety problems. Other metrics such as degree centrality and betweenness centrality, which were used to determine the control and influence flow of networks, were not important differentiators of the high and low safety performing teams (Alsamadani et al., 2013). On the other hand, network density and centrality measures were significant measures when used to investigate the correlation between the safety communication networks and safety climate. Subcontractors who exhibited a higher density and lower betweenness centrality in a communication network had better safety climates (Liao et al., 2014a). Liao et al. (2014b) used degree centrality and betweenness centrality to assess the actors' roles in authorizing and controlling information in the safety communication network. Network density, centrality measures, clustering coefficient, average path length, and modularity also proved to be useful in the evaluation of safety performance and system resilience by preventing risks using simulated agent-based modelling. Modular was used to divide the network into different community structures for observation. Cluster groups that reflected the teams' existence on the site were identified through the clustering coefficient. Higher degree centrality of the upper management indicated that they were influential and that more responsibility for safety was entrusted to them. A high betweenness and low closeness bridged the gap and encouraged communications flow. Low closeness 
centrality and average path length also revealed a connected safety network that had a low incident rate (Wehbe et al., 2016).

For accident networks, a higher out-nodal degree indicated the cause of an accident that triggered more accidents. Zhou and Irizarry (2016) used the clustering coefficient to identify the causes of accidents with similar characteristics. The diameter and average path length were used to identify the distance of a cause of an accident from another. Causes of accidents with similar average path lengths in a random network were deemed to have a small-world attribute that was difficult to control as they exhibited faster propagation than that of a regular network.

\section{Discussions and Conclusions}

This review has systematically combined 38 SNA metrics and concepts in 9 complex project management knowledge areas. Fig. 2 illustrates the 39 most frequently occurring keywords extracted from the 65 referenced papers which were related to SNA applications in complex project management. The bigger the font size of the keywords, the more frequently it appears in the references of this study. Here, "centrality," "connected," "communication," "risk," and "stakeholder," are the underpinned keywords adopted in the reviewed papers which reflect the common applications of SNA. It also shows the connection among complex projects keywords, such as "different," "emergence," "difficulty," "dynamic," and "evolution" and complex project management knowledge areas, such as "risk management," "procurement management," "stakeholder management," “communication management," "quality management," "schedule management," and "resource management" with the SNA common keywords, suggesting that SNA is a useful tool for analyzing complex project networks.

The demonstration of the application of SNA using UCINET software as in Table 4 provides a practical example to practitioners and researchers on how SNA can be applied in 
their case studies. While there are many SNA software products available on the market, UCINET was selected as this program is specially designed for the users who are not technically oriented but who require a tool that features many SNA metrics to characterize the overall networks and the positions of nodes within networks (Borgatti et al., 2014).

From a practical perspective, the SNA metrics and concepts such as brokerage, boundary spanners, homophily, reciprocity, transitivity, giant component, small-world, modularity, and partitioning, identified in the study, can be used as practical tools for analyzing the complex relationships among stakeholders and to determine new relationships for engineering projects and construction organizational strategic planning. For instance, giant component can be applied to existing client and contractor hierarchical structure networks to improve the transmission efficiency, and the small-world properties of consultation networks can be used to improve interdisciplinary interactions that lead to technology innovation and reduced engineering errors (Lin, 2014). Risks arising from technical, organizational, and environmental complexity can be analyzed using SNA to investigate the interrelationships between risk and accidental factors, as described in Li et al. (2016), Mohammadfam et al. (2015), Yang and Zhou (2014), and Zhou and Irrizary (2016). Additionally, the uses of SNA are not limited to social studies for analyzing trust, communications, and other social structure networks, but the practitioners can also extend the uses of SNA to broader complex project management areas that involve interdependencies between activities and resources. This is evident from work conducted on project trade networks (Wambeke et al., 2012; Wambeke et al., 2013), defect causes networks (Aljassmi et al., 2013), project practices networks (Pishdad-Bozorgi et al., 2016), highway data-information-decisions networks (Woldesenbet et al., 2015), traffic networks (El-Adaway et al., 2016), water distribution networks (Dunn and Wilkinson, 2013), risk networks (Li et al., 2016; Yang and Zou, 2014), and accident networks (Zhou and Irrizary, 2016). 
SNA could be a useful tool for analyzing the structural complexity of complex projects. As demonstrated by the work of examining essential flash track practices for successful project execution (Pishdad-Bozorgi et al., 2016), one of the fundamental advantages of SNA is its ability to examine the dependencies between tasks and identify the interrelationships between them. SNA is applied to quality management for tasks such as the analysis of jobsite networks to discover underlying problems (Lin, 2014) and the investigation of the task and organizational network interdependence to identify misalignments that impede project effectiveness (Chinowsky et al., 2011), which could promote lean practices in complex project management. Reciprocal complexity issues arising in complex projects have led to serious interface problems between different project disciplines (Baccarini, 1996). This includes problems such as project participants belonging to different linguistic and cultural backgrounds, which affects the trust level among them (Bosch-Rekveldt et al., 2011). SNA can also be integrated with inter-organizational systems to select team members who share common values and trust and who could cooperate to ensure the successful implementation of projects (Zhang et al., 2016). In the same context, SNA can be used to analyze crosscultural interactions among global project participants (Di Marco et al., 2010; Di Marco et al., 2012), and examine team coordination (Hossain, 2009a; Hossain, 2009b; Hossain and Wu, 2009).

The review also reveals that SNA could be potentially used as an effective tool to examine the uncertainty and dynamic change of complex project networks. SNA could identify the construction trades associated with the variation and support decision-making in targeting trades to reduce that variation (Wembeke et al., 2014). Risk factors that interlink with project stakeholders (Yang and Zhou, 2014; Li et al., 2016) could be used to determine the stakeholders' risk factors and evaluate the effect of these risks from the network perspectives. In terms of organizational context, SNA is revealed as a powerful tool for examining the 
dynamic change of inter-organizational collaborative relationships. It could be used in conjunction with an agent-based modeling to simulate various collaborative behavior (Son and Rojas, 2011) for determining a strategic relationship.

The application of SNA to complex projects should not only be limited to social boundaries, but should go beyond to address more uncertainty issues and dynamic interaction relationships across different project management knowledge areas to improve the performance of complex projects. Future research should advance the SNA model that influences the dynamic nature of complex projects, particularly those related to the fragmentation of organizations and the spread of risks. Note that the present study did not consider aspects such as the formulas and parameters of SNA metrics, static or dynamic analytical paradigms, and the factors that influence the accuracy of SNA metrics. Some of the SNA metrics and concepts discussed in the selected publications may also have been overlooked.

\section{Acknowledgements}

This project was partly funded by the Australian Research Council (ARC) linkage scholarship \#53187 and discovery project \#DP170104612, and National Science Foundation of China \#51578317.

\section{References}

Ahern, T., Leavy, B., \& Byrne, P. J. (2014). "Complex project management as complex problem solving: A distributed knowledge management perspective." Int. J. Proj. Manage., 32(8), 1371-1381.

Ahuja, M.K., Galletta, D.F. and Carley, K.M. (2003). "Individual centrality and performance in virtual R\&D groups: An empirical study.” Manage. Sci., 49(1), 21-38. 
Akgul, B.K., Ozorhon, B., Dikmen, I. and Birgonul, M.T. (2016). "Social network analysis of construction companies operating in international markets: case of Turkish contractors." J. Civ. Eng. \& Manage., 1-11.

Alba, R. (1973). "A graph-theoretic definition of a sociometric clique." The J. Math. Sociol., 3(1), 113-126.

Aljassmi, H., Han, S. and Davis, S. (2013). "Project pathogens network: New approach to analyzing construction-defects-generation mechanisms." J. Constr. Eng. Manage,, 140(1), 1-11.

Almahmoud, E. and Doloi, H.K. (2015). “Assessment of social sustainability in construction projects using social network analysis." Facilities, 33(3/4), 152-176.

Alsamadani, R., Hallowell, M. and Javernick-Will, A.N. (2013). "Measuring and modelling safety communication in small work crews in the US using social network analysis." Constr. Manage. Econ., 31(6), 568-579.

Alsamadani, R., Hallowell, M.R., Javernick-Will, A. and Cabello, J. (2013a). "Relationships among language proficiency, communication patterns, and safety performance in small work crews in the United States.” J. Constr. Eng. Manage., 139(9), 1125-1134.

Arriagada D, R.E. and Alarcón C, L.F. (2013). "Knowledge Management and Maturation Model in Construction Companies.” J. Constr. Eng. Manage., 140(4), B4013006.

Baccarini, D. (1996)." The concept of project complexity—a review." Int. J. Proj. Manage., 14(4), 201-204.

Badi, S., Wang, L. and Pryke, S. (2017). "Relationship marketing in Guanxi networks: A social network analysis study of Chinese construction small and medium-sized enterprises.” Ind. Mktg. Manage, 60, 204-218. 
Barranquero, J., Chica, M., Cordón, O., \& Damas, S. (2015). Detecting key variables in system dynamics modelling by using social network metrics. In Advances in Artificial Economics (pp. 207-217). Springer International Publishing.

Blackburn, S. (2002). "The project manager and the project-network." Int. J. Proj. Manage., 20(3), 199-204.

Bonacich, P. (1987). "Power and centrality: A family of measures." American J. Sociol., 92(5), 1170-118.

Borgatti, S. P., Everett, M. G., and Freeman, L. C. (2002). UCINET for windows: Software for social network analysis. Analytic Technologies, Harvard, MA.

Borgatti, S.P. (2005). “Centrality and network flow.” Soc. Net., 27(1), 55-71.

Borgatti, S.P. and Everett, M.G. (1997). "Network analysis of 2-mode data." Soc. Net., 19(3), 243-269.

Borgatti, S. P., \& Foster, P. C. (2003). "The network paradigm in organizational research: A review and typology." J. Manage., 29(6), 991-1013.

Borgatti, S. P., Everett, M. G., \& Freeman, L. C. (2014). Ucinet. In Encyclopedia of social network analysis and mining (pp. 2261-2267). Springer New York.

Bosch-Rekveldt, M., Jongkind, Y., Mooi, H., Bakker, H., \& Verbraeck, A. (2011). "Grasping project complexity in large engineering projects: The TOE (Technical, Organizational and Environmental) framework." Int. J. Proj. Manage., 29(6), 728-739.

Brady, T., \& Davies, A. (2014). "Managing structural and dynamic complexity: A tale of two projects." Proj. Manage. J., 45(4), 21-38.

Brass, D. J. (1981). "Structural relationships, job characteristics, and worker satisfaction and performance.” Admin. Sci. Quarterly, 331-348.

Brass, D. J. (1984). "Being in the right place: A structural analysis of individual influence in an organization.” Admin. Sci. Quarterly, 518-539. 
Brass, D. J., \& Burkhardt, M. E. (1993). "Potential power and power use: An investigation of structure and behavior.” Acad. Manage. J., 36(3), 441-470.

Brass, D. J., Butterfield, K. D., \& Skaggs, B. C. (1998). Relationships and unethical behavior: A social network perspective. Acad. Manage. Review, 23(1), 14-31.

Brin, S. \& Page, L. (1998). "The anatomy of a large-scale hypertextual Web search engine." Comp. Net. ISDN Sys., 30(1-7) 107-17.

Bruggeman, J. (2013). “Social networks: An introduction”. Routledge, New York.

Cadini, F., Zio, E., and Petrescu, C.A. (2009). Using centrality measures to rank the importance of the components of a complex network infrastructure, Critical information infrastructure security, in R. Setola and S. Geretshuber (Eds.), Springer, Berlin, 155-167.

Cao, D., Li, H., Wang, G., Luo, X., Yang, X. and Tan, D. (2016). “Dynamics of ProjectBased Collaborative Networks for BIM Implementation: Analysis Based on Stochastic Actor-Oriented Models.” J. Manage. Eng., p.04016055.

Chang, S. and Zhang, Q. (2013). "Discrete Core/Periphery Structure Characters of C2 Organizations Analysis Based on SNA.” Int. Conf. on Info. Tech. Manage. Sci., 813821.

Chinowsky, P., \& Taylor, J. E. (2012). "Networks in engineering: an emerging approach to project organization studies.” Eng. Proj. Org. J., 2(1-2), 15-26.

Chinowsky, P., Taylor, J.E. and Di Marco, M. (2011). "Project network interdependency alignment: New approach to assessing project effectiveness.” J. Manage. Eng., 27(3), 170-178.

Chinowsky, P.S., Diekmann, J. and O’Brien, J. (2010). "Project organizations as social networks." J. Constr. Eng. Manage., 136(4), 452-458. 
Chowdhury, A.N., Chen, P.H. and Tiong, R.L. (2011). "Analysing the structure of publicprivate partnership projects using network theory." Const. Manage. Econ., 29(3), 247260.

College of Complex Project Managers, and Defence Materiel Organisation (CCPM) (2008). "Competency standard for complex project managers." Version 3.3, Commonwealth of Australia, Dept. of Defence, Canberra, Australia.

Complex Project Manager Competency Standards (CCPMS) (2012). V.4.1, August. Defense Material Organisation, Department of Defense, Australian Government, Australia.

Comu, S., Iorio, J., Taylor, J.E. and Dossick, C.S. (2013). "Quantifying the impact of facilitation on transactive memory system formation in global virtual project networks." J. Constr. Eng. Manage., 139(3), 294-303.

CPC, 2013. Contract for Complex Projects. Published by the Chartered Institute of Building, United Kingdom.

Davenport, A. J., Gefflot, C., and Beck, J. C. (2001). "Slack-based techniques for robust schedules." Constraints and Uncertainty Workshop, 7th Int. Conf. on Principles and Practice of Constraint Programming, Paphos, Cyprus.

Davies, A., \& Mackenzie, I. (2014). "Project complexity and systems integration: Constructing the London 2012 Olympics and Paralympics Games." Int. J. Proj. Manage., 32(5), 773-790.

De Nooy, W., Mrvar, A. and Batagelj, V. (2011). Exploratory social network analysis with Pajek. Cambridge University Press, New York, USA.

Demeulemeester, E. L., and Herroelen, W. S. (2002). Project scheduling: A research handbook. Kluwer Academic Publishers, Boston.

Di Marco, M.K., Alin, P. and Taylor, J.E. (2012). "Exploring negotiation through boundary objects in global design project networks.” Proj. Manage. J., 43(3), 24-39. 
Di Marco, M.K., Taylor, J.E. and Alin, P. (2010). "Emergence and role of cultural boundary spanners in global engineering project networks." J. Manage. Eng., 26(3), 123-132.

Dogan, S.Z., Arditi, D., Gunhan, S. and Erbasaranoglu, B. (2014). “Assessing coordination performance based on centrality in an e-mail communication network." J. Manage. Eng., 31(3), 04014047.

Doloi, H. (2012). “Assessing stakeholders' influence on social performance of infrastructure projects." Facilities, 30(11/12), 531-550.

Dunn, S. and Wilkinson, S.M. (2013). "Identifying critical components in infrastructure networks using network topology.” J. Infra. Sys., 19(2), 157-165.

El-adaway, I.H., Abotaleb, I.S. and Vechan, E. (2016). "Social Network Analysis Approach for Improved Transportation Planning.” J. Infra. Sys., 05016004.

Estrada, E. and Rodriguez-Velazquez, J.A. (2005). "Subgraph centrality in complex networks." Phys. Review, 71(5), 056103.

Faust, K. (1997). “Centrality in affiliation networks.” Soc. Net., 19(2), 157-191.

Federal Highway Administration (FHWA). (2010). "Project delivery defined: Major project." 〈http://www.fhwa.dot.gov/ipd/project_delivery/ defined/major_project.htm〉(May 31, 2017).

Geraldi, J., Maylor, H., \& Williams, T. (2011). "Now, let's make it really complex (complicated) A systematic review of the complexities of projects." Int. J. Op. \& Prod. Manage., 31(9), 966-990.

Gerassis, S., Martín, J. E., García, J. T., Saavedra, A., \& Taboada, J. (2017). "Bayesian decision tool for the analysis of occupational accidents in the construction of embankments." J. Constr. Eng. \& Manage., 04016093.

Grant, M. J., \& Booth, A. (2009). “A typology of reviews: an analysis of 14 review types and associated methodologies." Health Info. \& Libraries J., 26(2), 91-108. 
Granovetter, M.S. (1973). “The strength of weak ties.” American J. Soc., 1360-1380.

Guimera, R., Mossa, S., Turtschi, A., and Amaral, L. A. N. (2005). "The worldwide air transportation network: Anomalous centrality, community structure, and cities' global roles." Proc. Natl. Acad. Sci. U.S.A., 102(22), 7794-7799.

Hall, N., and Posner, M. (2004). "Sensitivity analysis for scheduling problems." $J$. Scheduling, 7, 49-83.

Heng, K.S.H. and Loosemoore, M. (2013). "Structural holes in hospital organisations." Eng. Constr. Arch. Manage., 20(5): 474 - 487.

Hernandez-Garcia, A. and Suarez-Navas, I. (2017). GraphFES: A web service and application for Moodle message board social graph extraction. In Big Data and Learning Analytics in Higher Education (167-194), Springer International Publishing.

Hossain, L. (2009a). "Effect of organisational position and network centrality on project coordination.” Int. J. Proj. Manage., 27(7), 680-689.

Hossain, L. (2009b). "Communications and coordination in construction projects." Constr. Manage. Econ., 27(1), 25-39.

Hossain, L. and Wu, A. (2009). "Communications network centrality correlates to organisational coordination.” Int. J. Proj. Manage., 27(8), 795-811.

Houghton, R.J., Baber, C., Stanton, N.A., Jenkins, D.P. and Revell, K. (2015). “Combining network analysis with Cognitive Work Analysis: insights into social organisational and cooperation analysis." Ergonomics, 58(3), 434-449.

Ignatius, J., Leen, J. Y. A., Ramayah, T., Hin, C. K., \& Jantan, M. (2012). "The impact of technological learning on NPD outcomes: The moderating effect of project complexity." Technovation, 32(7), 452-463.

Javernick-Will, A. (2011). "Knowledge-sharing connections across geographical boundaries in global intra-firm networks." Eng. Proj. Org. J., 1(4), 239-253. 
Katz, L. (1953). "A new status index derived from sociometric analysis." Psychometrika, 18, $39-43$.

Kleinbaum, A.M., Stuart, T.E. and Tushman, M.L. (2013). "Discretion within constraint: Homophily and structure in a formal organization.” Org. Sci., 24(5), 1316-1336.

Labianca, G., \& Brass, D. J. (2006). "Exploring the social ledger: Negative relationships and negative asymmetry in social networks in organizations." Acad. Manage. Review, 31(3), 596-614.

Labianca, G., Brass, D. J., \& Gray, B. (1998). "Social networks and perceptions of intergroup conflict: The role of negative relationships and third parties." Acad. Manage. J., 41(1), $55-67$.

Larsen, G.D. (2011). "Understanding the early stages of the innovation diffusion process: awareness, influence and communication networks." Constr. Manage. Econ., 29(10), 987-1002.

Lee, Y.S., Kim, J.J. and Lee, T.S. (2016). "Topological Competiveness Based on Social Relationships in the Korean Construction-Management Industry." J. Constr. Eng. Manage., 05016014.

Leu, S.S. and Chang, C.M. (2015). "Bayesian-network-based fall risk evaluation of steel construction projects by fault tree transformation." J. Civ. Eng. Manage., 21(3), 334342.

Li, C.Z., Hong, J., Xue, F., Shen, G.Q., Xu, X. and Mok, M.K. (2016). "Schedule risks in prefabrication housing production in Hong Kong: a social network analysis." J. Cleaner Prod., 134, 482-494.

Li, Y.K., Lu,Y.J., Kwak,Y.H., Le,Y. and He,Q.H. (2011). "Social network analysis and organizational control in complex projects: construction of EXPO 2010 in China.” Eng. Proj. Org. J., 1(4), 223-237. 
Liao, P.C., Lei, G., Fang, D. and Liu, W. (2014a). "The relationship between communication and construction safety climate in China.” KSCE J. C. Eng., 18(4), 887-897.

Liao, P.C., Lei, G., Xue, J. and Fang, D. (2014b). "Influence of person-organizational fit on construction safety climate.” J. Manage. Eng., 31(4), 04014049.

Liebowitz, J. (2006). Strategic intelligence: business intelligence, competitive intelligence, and knowledge management. CRC Press, Florida, United States.

Lin, C.L. and Tan, H.L. (2014). "Performance measurement in the public sector: Example of the building administration authorities in Taiwan.” J. Manage. Eng., 30(1), 97-107.

Lin, S.C. (2014). "An analysis for construction engineering networks." J. Constr. Eng. Manage., 141(5), 04014096.

Liu, L., Borman, M., \& Gao, J. (2014). "Delivering complex engineering projects: Reexamining organizational control theory.” Int. J. Proj. Manage., 32(5), 791-802.

Liu, L., Han, C. and Xu, W. (2015). "Evolutionary analysis of the collaboration networks within National Quality Award Projects of China.” Int. J. Proj. Manage., 33(3), 599609

Loosemore, M. (1998). "Social network analysis: using a quantitative tool within an interpretative context to explore the management of construction crises." Eng. Constr. Arch. Manage., 5(4), 315-326.

Lu, Y., Li, Y., Da, P. and Zhang, Y. (2015). "Organizational network evolution and governance strategies in megaprojects." Constr. Econ. Build., 15(3), 19.

Maoz, Z. (2010). Networks of nations: The evolution, structure, and impact of international networks. Cambridge University Press, USA, 1816-2001.

Marsden, P.V. (1993). "The reliability of network density and composition measures." Soc. Net., 15(4), 399-421. 
McCormick, R., Fox, A., Carmichael, P. and Procter, R. (2010). Researching and understanding educational networks. Routledge, Abidon, Oxon.

McCulloh, Ian and Lospinoso, Joshua and Carley, Kathleen M. (2010)."The Link Probability Model: A Network Simulation Alternative to the Exponential Random Graph Model." <https://ssrn.com/abstract=2729285 or http://dx.doi.org/10.2139/ssrn.2729285> (May $31,2017)$

Mead, S.P. (2001). "Using social network analysis to visualize project teams." Proj. Manage. J., 32(4), 32-38.

Mohammadfam, I., Bastani, S., Esaghi, M., Golmohamadi, R. and Saee, A. (2015). "Evaluation of coordination of emergency response team through the social network analysis, Case study: Oil and gas refinery." Safety and health at work, 6(1), 30-34.

Moher, D., Liberati, A., Tetzlaff, J., Altman, D. G., \& Prisma Group. (2009). "Preferred reporting items for systematic reviews and meta-analyses: the PRISMA statement." PLoS med, 6(7), e1000097.

Naderpajouh, N., \& Hastak, M. (2014). “Quantitative analysis of policies for governance of emergent dynamics in complex construction projects." Constr. Manage. \& Econ., 32(12), 1222-1237.

Neleman J (2006)."Shell gaat diep." FEM Bus, 9(4):30-34

Nelson, R. E. (1989). “The strength of strong ties: Social networks and intergroup conflict in organizations.” Acad. Manage. J., 32(2), 377-401.

Nguyen, A. T., Nguyen, L. D., Le-Hoai, L., \& Dang, C. N. (2015). "Quantifying the complexity of transportation projects using the fuzzy analytic hierarchy process." Int. J. Proj. Manage., 33(6), 1364-1376. 
Nik-Bakht, M., and El-Diraby, T. (2016). "Communities of interest-interest of communities: Social and semantic analysis of communities in infrastructure discussion networks." Comp. Aid. Civ. Infra. Eng., 31(1), 34-49.

Park, H., Han, S.H., Rojas, E.M., Son, J. and Jung, W. (2011). "Social network analysis of collaborative ventures for overseas construction projects.” J. Constr. Eng. Manage., 137(5), 344-355.

Pauget, B. and Wald, A. (2013). "Relational competence in complex temporary organizations: The case of a French hospital construction project network." Int. J. Proj. Manage., 31(2), 200-211.

Pishdad-Bozorgi, P., Austin, R.B. and de la Garza, J.M. (2016). 'Network Analysis of FlashTrack Practices." J. Manage. Eng., p.04016024.

PMI (2013). A Guide to the Project Management Body of Knowledge (PMBOK® Guide). Fifth Edition. Pennsylvania: Project Management Institute (PMI).

PMI-Construction Extension, 2016. The Construction Extension to the PMBOK Guide. Pennsylvania: Project Management Institute (PMI).

Priven, V. and Sacks, R. (2015). "Effects of the last planner system on social networks among construction trade crews.” J. Constr. Eng. Manage., 141(6), 04015006.

Pryke, S.D. (2005). "Towards a social network theory of project governance." Constr. Manage. Econ., 23(9), 927-939.

Pryke, S.D. (2006). "Legal issues associated with emergent actor roles in innovative UK procurement: prime contracting case study." J. Prof. Issues Eng. Edu. Prac., 132(1), 67-76.

Pryke, S.D. (2012). Social Network Analysis in Construction. Wiley Blackwell, London, UK. Pryke, S.D. and Pearson, S. (2006). "Project governance: case studies on financial incentives." Build. Research \& Info., 34(6), 534-545. 
Pryke, S., and Smyth, H. (2006). The management of complex projects: A relationship approach. Blackwell Publishing Ltd., Oxford, UK.

Pryke, S.D., Zagkli, G. and Kougia, I. (2011). "Resource provision ego-networks in small Greek construction firms.” Build. Research \& Info., 39(6), 616-636.

Qureshi, S. M., \& Kang, C. (2015). "Analysing the organizational factors of project complexity using structural equation modelling." Int. J. Proj. Manage., 33(1), 165-176.

Ruan, X., Ochieng, E.G., Price, A.D. and Egbu, C.O. (2012). "Knowledge integration process in construction projects: a social network analysis approach to compare competitive and collaborative working." Constr. Manage. Econ., 30(1), 5-19.

Sabuncuoglu, I., and Bayiz, M. (2000). "Analysis of reactive scheduling problems in a job shop environment.” Eur. J. Oper. Res., 126(3), 567-586

Santandrea, M., Sironi, A., Grassi, L. and Giorgino, M. (In Press). "Concentration risk and internal rate of return: Evidence from the infrastructure equity market." Int. J. Proj. Manage.

Schoenenberger, L. K., \& Schenker-Wicki, A. (2015). Can System Dynamics Learn from Social Network Analysis? <https://papers.ssrn.com/sol3/papers.cfm?abstract_id=2550593>(May 31, 2017)

Sedita, S.R. and Apa, R. (2015). "The impact of inter-organizational relationships on contractors' success in winning public procurement projects: The case of the construction industry in the Veneto region.” Int. J. Proj. Manage., 33(7), 1548-1562.

Shenhar, A. J. (2001). "One size does not fit all projects: Exploring classical contingency domains." Manage. Sci., 47(3), 394-414.

Slowinski, R., and Hapke, M. (2000). Scheduling under fuzziness, Physica, Heidelberg, Germany. 
Solis, F., Sinfield, J.V. and Abraham, D.M. (2013). "Hybrid approach to the study of interorganization high performance teams.” J. Constr. Eng. Manage., 139(4), 379-392.

Son, J. and Rojas, E.M. (2011). "Evolution of collaboration in temporary project teams: an agent-based modeling and simulation approach.” J. Constr. Eng. Manage., 137(8), 619628.

Stinchcombe, A.L. (1959). "Bureaucratic and craft administration of production: A comparative study." Admin. Sci. Quarterly, 168-187.

Swan, W., McDermott, P. and Khalfan, M. (2007). "The application of social network analysis to identify trust-based networks in construction.” Int. J. Networking \& Virtual Org., 4(4), 369-382.

Tang, Y. (2012). "Knowledge Transferring Features in Traditional Construction Project Team in China: Based on SNA.” Tech. \& Invest., 3(04), 230.

Tavakoli, A., \& Riachi, R. (1990). "CPM use in ENR top 400 contractors." J. Manage. Eng., 6(3), 282-295.

Thorpe, T. and Mead, S. (2001). "Project-specific web sites: Friend or foe?" J. Constr. Eng. Manage., 127(5), 406-413.

Torres, J.M., Duenas-Osorio, L., Li, Q. and Yazdani, A. (2016). "Exploring Topological Effects on Water Distribution System Performance Using Graph Theory and Statistical Models.” J. Water Resources Plan. Manage., p.04016068.

Vidal, L. A., Marle, F., \& Bocquet, J. C. (2011). "Measuring project complexity using the Analytic Hierarchy Process.” Int. J. Proj. Manage., 29(6), 718-727.

Wambeke, B.W., Liu, M. and Hsiang, S.M. (2012). "Using Pajek and centrality analysis to identify a social network of construction trades.” J. Constr. Eng. Manage., 138(10), 1192-1201. 
Wambeke, B.W., Liu, M. and Hsiang, S.M. (2013). "Task variation and the social network of construction trades.” J. Manage. Eng., 30(4), 05014008.

Wanberg, J., Javernick-Will, A., Chinowsky, P. and Taylor, J.E. (2014). "Spanning cultural and geographic barriers with knowledge pipelines in multinational communities of practice.” J. Constr. Eng. Manage., 141(4), 04014091.

Wang, Y., Le, Y., \& Dai, J. (2014). "Incorporation of alternatives and importance levels in scheduling complex construction programs." J. Manage. Eng., 31(6), 04014098.

Wasserman, S., and Faust, K. (1997). Social network analysis: Methods and applications. Cambridge University Press, Cambridge, UK.

Wehbe, F., Al Hattab, M. and Hamzeh, F. (2016). "Exploring associations between resilience and construction safety performance in safety networks." Safety Sci., 82, 338-351.

West, J. (2014). "Collaborative patterns and power imbalance in strategic alliance networks." J. Constr. Eng. Manage., 140(6), p.04014010.

Whitty, S. J., \& Maylor, H. (2009)." And then came complex project management (revised)." Int. J. Proj. Manage., 27(3), 304-310.

Williams TM (2002). Modelling complex projects. Wiley, London.

Williams TM (2005). "Assessing and moving on from the dominant project management discourse in the light of project overruns." IEEE Trans Eng Manage., 52(4):497-508.

Williams, N.L., Ferdinand, N. and Pasian, B. (2015). “Online Stakeholder Interactions in the Early Stage of a Megaproject.” Proj. Manage. J., 46(6), 92-110.

Williams, T.M. (1999). "The need for new paradigms for complex projects." Int. J. Proj. Manage., 17(5), pp.269-273.

Woldesenbet, A., Jeong, H.D. and Park, H. (2015). "Framework for integrating and assessing highway infrastructure data." J. Manage. Eng., 32(1), p.04015028. 
Wong, K., Unsal, H., Taylor, J.E. and Levitt, R.E. (2009). "Global dimension of robust project network design.” J. Constr. Eng. Manage., 136(4), pp.442-451.

Yang, J., Shen, G.Q., Ho, M., Drew, D.S. and Xue, X. (2011). "Stakeholder management in construction: An empirical study to address research gaps in previous studies." Int. J. Proj. Manage., 29(7), 900-910.

Yang, R.J. and Zou, P.X. (2014). "Stakeholder-associated risks and their interactions in complex green building projects: A social network model.” Build. \& Env., 73, 208-222.

Yugue, R. T., \& Maximiano, A. C. A. (2012, June). "Contribution to the research of project complexity and management processes." In Management of Innovation and Technology (ICMIT) International Conference, 668-673, IEEE.

Zhang, L., Cheng, J. and Fan, W. (2015). "Party Selection for Integrated Project Delivery Based on Interorganizational Transactive Memory System.” J. Constr. Eng. Manage., 142(3), 04015089.

Zhang, L., He, J. and Zhou, S. (2013). "Sharing tacit knowledge for integrated project team flexibility: Case study of integrated project delivery." J. Constr. Eng. Manage., 139(7), 795-804.

Zhang, L., Wu, X., Skibniewski, M.J., Zhong, J. and Lu, Y. (2014). "Bayesian-network-based safety risk analysis in construction projects.” Reliability Eng. \& Sys. Safety, 131, 29-39.

Zheng, X., Le, Y., Chan, A.P., Hu, Y. and Li, Y. (2016). "Review of the application of social network analysis (SNA) in construction project management research." Int. J. Proj. Manage., 34(7), 1214-1225.

Zhou, Z., \& Irizarry, J. (2016). "Integrated Framework of Modified Accident Energy Release Model and Network Theory to Explore the Full Complexity of the Hangzhou Subway Construction Collapse.” J. Manage. Eng., 32(5), 05016013. 


\section{Table Captions List}

Table 1. Complex Project Management Knowledge Areas

Table 2. Titles of Journals

Table 3. Papers Reviewed in the Study

Table 4. Degree centrality of SNA metrics and concepts in complex project management knowledge areas 
Table 1. Complex Project Management Knowledge Areas

\begin{tabular}{|c|c|}
\hline Knowledge Area & Description \\
\hline Network Behavior & $\begin{array}{l}\text { Involves the analysis of human interaction behaviors (Pryke and } \\
\text { Smyth, 2006) such as inter- and intra-project or organizational } \\
\text { relationships }\end{array}$ \\
\hline Stakeholder & Relates to the management of stakeholder engagement such as the \\
\hline Management & $\begin{array}{l}\text { processes of identifying people, groups, or organizations that } \\
\text { could impact or be impacted by the project, and adopting effective } \\
\text { project management strategies to engage them actively in project } \\
\text { decisions and execution }\end{array}$ \\
\hline Schedule & Covers any time-related processes and activities that contribute to \\
\hline Management & $\begin{array}{l}\text { project completion, and involves the definition of the activity, } \\
\text { sequencing the activity, activity resource and duration estimating, } \\
\text { schedule development, monitoring, and controlling }\end{array}$ \\
\hline Quality Management & $\begin{array}{l}\text { Ensures that all processes involved in the complex project system } \\
\text { satisfy project requirements such as quality planning, quality } \\
\text { assurance, and quality monitor and control. The quality planning } \\
\text { described in this paper extends the scope to include the } \\
\text { improvement of quality in the works involved from planning to } \\
\text { completion. }\end{array}$ \\
\hline Resources & Refers to the management of human resources, machinery and \\
\hline Management & $\begin{array}{l}\text { tools, equipment, bulk materials, etc., and includes the mobilizing, } \\
\text { utilizing, and demobilizing of resources }\end{array}$ \\
\hline
\end{tabular}


Communications

Management

Risk Management

Procurement

Management

Health,

Security,

Environmental

(HSSE) Management
Involves the communication planning, managing, monitoring, and controlling of the information flow to ensure the effective and efficient generation and distribution of information

Deals with the identification, planning, analysis, management, monitoring, and controlling of positive and negative events connected to stakeholders' interests

Deals with the procurement of contractual arrangements between a multitude of clients and contractors, sellers, and buyers, and includes the procurement of capital, project equipment, and materials

Safety, Involves the planning, execution, monitoring, and control of the and health, safety, security, and environmental aspects of complex projects 
Table 2. Titles of Journals

\section{Title of Journals}

Building and Environment

Building Research and Information

Computer-Aided Civil and Infrastructure Engineering

Construction Economics and Building

Construction Management and Economics

Engineering Project Organization Journal

Engineering, Construction and Architectural Management

Ergonomics

Facilities

Industrial Marketing Management

International Journal of Networking and Virtual Organizations

International Journal of Project Management

Journal of Civil Engineering and Management

Journal of Cleaner Production

Journal of Construction Engineering and Management

Journal of Infrastructure Systems

Journal of Management in Engineering

Journal of Professional Issues in Engineering Education and Practice

KSCE Journal of Civil Engineering

Project Management Journal

Safety and Health at Work

Safety Science

Technology and Investment
No. of Papers

\section{1}

2

1

1

6

2

2

1

2

1

1

7

17

2

10

\section{1}

2

1

1

1 
Table 3. Papers Reviewed in the Study

\begin{tabular}{lll}
\hline Knowledge Area & References & No
\end{tabular}

Network Behavior $\quad$ Akgul et al. (2016); Cao et al. (2016); Liu et al. (2015); Lu et al. 7 (2015); Park et al., (2011); Sedita and Apa (2015); Son and Rojas (2011);

Stakeholder $\quad$ Almahmoud and Doloi (2015); Doloi (2012); Nik-Bakht and El- 7

Management Diraby (2016); Solis et al. (2013); Yang et al. (2011); Swan et al. (2007); Williams et al. (2015)

Schedule $\quad$ Wambeke et al., (2012); Wambeke et al. (2013) 2

Management

Quality Aljassmi et al. (2013); Dunn and Wilkinson (2013); El-Adaway 6

Management et al. (2016); Lin (2014); Pishdad-Bozorgi et al. (2016);

Woldesenbet et al. (2015)

Resources $\quad$ Badi et al. (2017); Larsen (2011); Li et al. (2011); Lin and Tan 5

Management (2014); Pryke et al. (2011)

Communications $\quad$ Arriagada and Alarcón, (2013); Chinowsky et al. (2010); 21

Management Chinowsky et al. (2011); Comu et al. (2013); Di Marco et al. (2010); Di Marco et al. (2012); Dogan et al., (2014); Heng and Loosemoore (2013); Hossain (2009a); Hossain, (2009b);

Hossain and Wu (2009); Houghton et al. (2015); Javernick-Will (2011); Loosemoore (1998); Pauget and Wald (2013); Priven and Sacks (2015); Ruan et al. (2012); Tang (2012); Thorpe and Mead (2001); Wanberg et al. (2014); Zhang et al. (2013)

Risk Management $\quad$ Li et al. (2016); Mohammadfam et al. (2015); Yang and Zou 4 (2014) 
Procurement $\quad$ Chowdhury et al. (2011); Lee et al. (2016); Pryke (2005); Pryke 8

Management (2006); Pryke and Pearson (2006); Santandrea et al. (in press);

West (2014); Zhang et al. (2015)

HSSE

Alsamadani et al. (2013); Alsamadani et al. (2013a); Liao et al. 6

Management

(2014a); Liao et al. (2014b); Wehbe et al. (2016); Zhou and

Irrizary (2016)

TOTAL 
Table 4. Degree centrality of SNA metrics and concepts in complex project management knowledge areas

\begin{tabular}{|c|c|c|}
\hline Rank & $\begin{array}{l}\text { SNA Metrics/Concepts in the } \\
\text { Complex Project Management } \\
\text { Knowledge Areas }\end{array}$ & Degree \\
\hline & SNA Metrics/ Concepts & \\
\hline 1 & Network Density & 0.889 \\
\hline 2 & Degree Centrality & 0.889 \\
\hline 3 & Betweenness Centrality & 0.889 \\
\hline 4 & In-Degree Centrality & 0.778 \\
\hline 5 & Tie Strength & 0.667 \\
\hline 6 & Average Path Length & 0.667 \\
\hline 7 & Brokerage & 0.667 \\
\hline 8 & Out-Degree Centrality & 0.556 \\
\hline 9 & Power & 0.556 \\
\hline 10 & Closeness Centrality & 0.556 \\
\hline 11 & Eigenvector Centrality & 0.556 \\
\hline 12 & Cohesion & 0.444 \\
\hline 13 & Diameter & 0.444 \\
\hline 14 & Clustering Coefficient & 0.444 \\
\hline 15 & Structural Equivalence & 0.444 \\
\hline 16 & Core or Periphery & 0.444 \\
\hline 17 & Ego Network & 0.444 \\
\hline 18 & Components & 0.444 \\
\hline 19 & Scale-Free/Power-Law & 0.333 \\
\hline
\end{tabular}




\begin{tabular}{|c|c|c|}
\hline 20 & Structural Holes & 0.333 \\
\hline 21 & Clique & 0.333 \\
\hline 22 & Small-world & 0.333 \\
\hline 23 & Direct Ties and Indirect Ties & 0.333 \\
\hline 24 & Modularity & 0.222 \\
\hline 25 & Homophily & 0.222 \\
\hline 26 & Boundary Spanner & 0.222 \\
\hline 27 & Cluster Analysis & 0.222 \\
\hline 28 & Transitivity & 0.222 \\
\hline 29 & Reciprocity & 0.222 \\
\hline 30 & Giant Component & 0.222 \\
\hline 31 & Partition & 0.222 \\
\hline 32 & Centrality & 0.222 \\
\hline 33 & Status Centrality & 0.222 \\
\hline 34 & Out Status Centrality & 0.222 \\
\hline 35 & Gap-Degree & 0.111 \\
\hline 36 & 2-step reach & 0.111 \\
\hline 37 & Point Connectivity & 0.111 \\
\hline 38 & $\begin{array}{l}\text { PageRank } \\
\text { Knowledge Areas }\end{array}$ & 0.111 \\
\hline 1 & Communications Management & 0.632 \\
\hline 2 & Procurement Management & 0.579 \\
\hline 3 & Network Behavior & 0.526 \\
\hline 4 & Stakeholder Management & 0.474 \\
\hline 5 & Quality Management & 0.368 \\
\hline
\end{tabular}




\begin{tabular}{|l|l|l|}
6 & Risk Management & 0.368 \\
7 & HSSE Management & 0.342 \\
8 & Resources Management & 0.263 \\
9 & Schedule Management & 0.079 \\
\hline
\end{tabular}




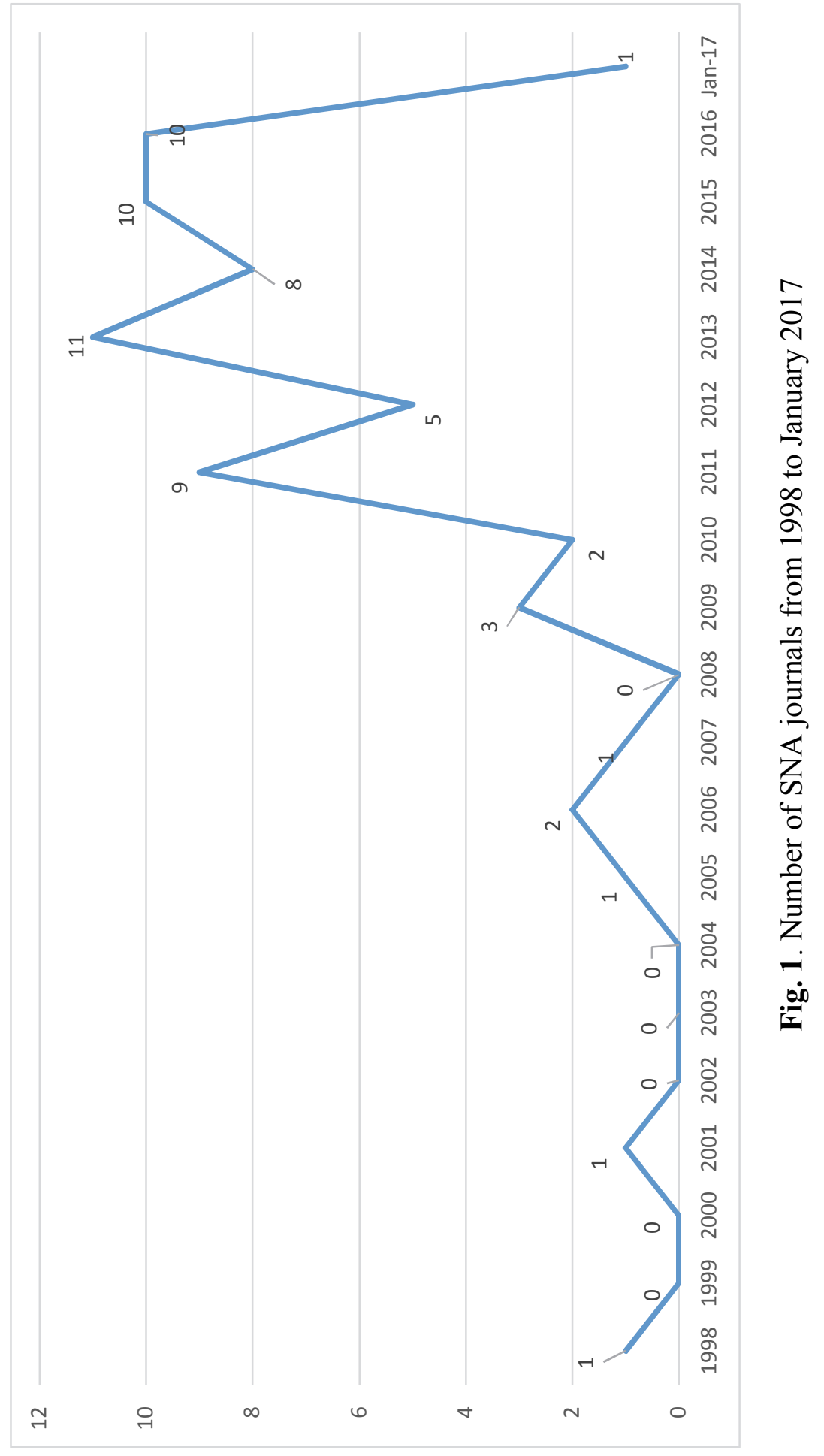




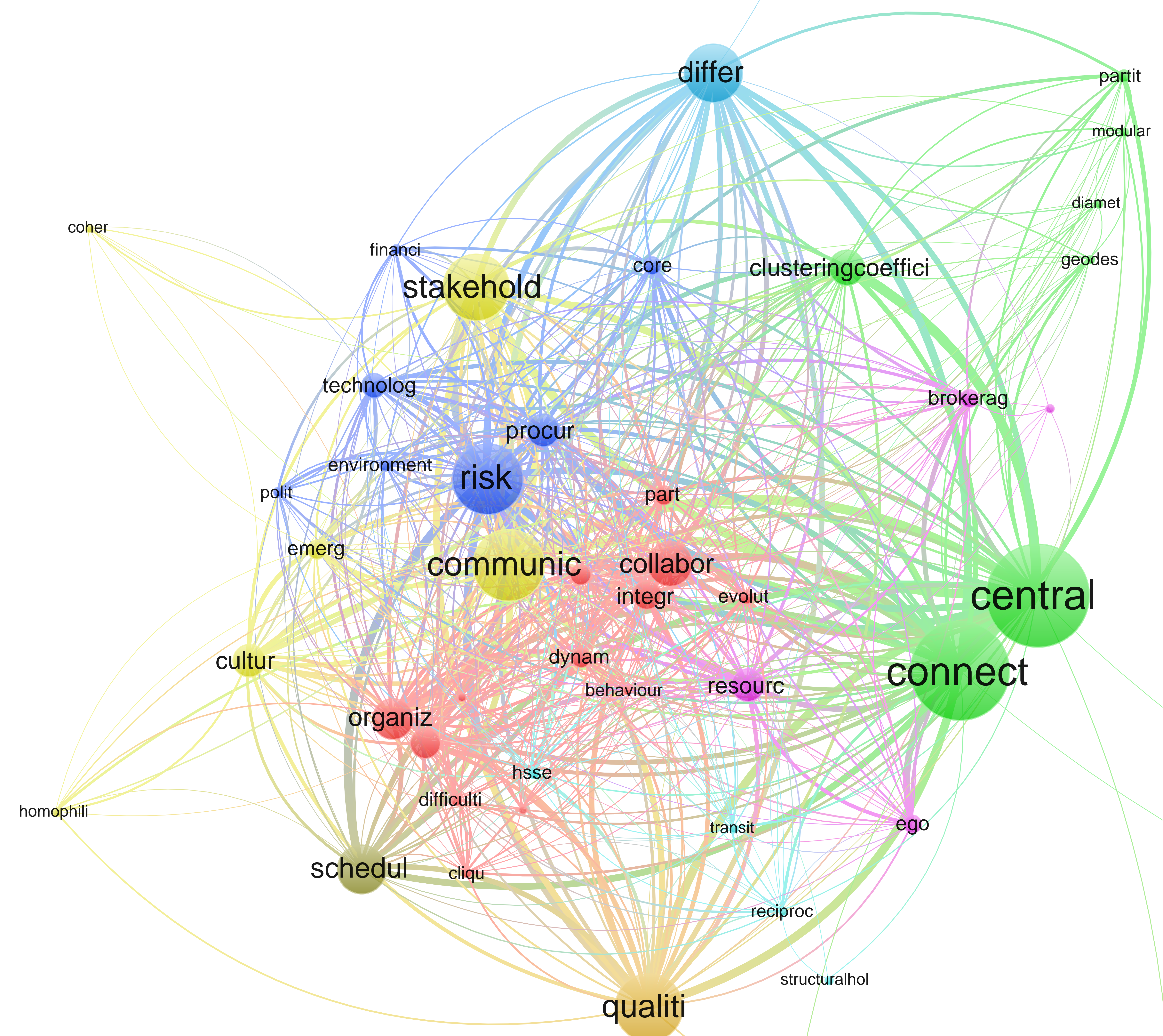

Fig. 2. Keyword co-occurence network: 1998 to January 2017 